\title{
ELECTRICAL AND THERMAL CONDUCTIVITIES OF SOME SULPHATE COMPOUNDS
}

\author{
M.M. ABDEL-Kader \\ Physics Department, Faculty of Science, Cairo University, Giza, Egypt \\ M.M. MOSAAD \\ Physics Department, Faculty of Education, Kafr El-Sheik, Egypt \\ S.A. Olofa, M.I. Abdel-Ati \\ Physics Department, Faculty of Science, Tanta University, Tanta, Egypt

$$
\text { AND A. El-Shawarby }
$$ \\ Physics Department, Faculty of Science, Zagazig University, Benha, Egypt
}

(Received May 12, 1992; revised version October 6, 1992)

The electrical conductivity $\sigma$ and the thermal conductivity $\lambda$ were investigated at varying temperature $\left(40<T<120^{\circ} \mathrm{C}\right)$ for two sulphate compounds, anhydrous mercury(II) sulphate $\mathrm{HgSO}_{4}$ and cerous(III) sulphate $\mathrm{Ce}_{2}\left(\mathrm{SO}_{4}\right)_{3} \cdot \mathrm{H}_{2} \mathrm{O}$. It seems likely that each of the two sulphate salts undergoes structural phase transition around $90^{\circ} \mathrm{C}$. The differential thermal analysis thermogram was carried out as an aid for confirming of the observed phase transitions. The mechanism of the heat transfer is mainly due to phonons. Interpretation of the obtained data was given on the basis of the reorientational motion of the $\mathrm{SO}_{4}^{--}$ions.

PACS numbers: 72.15.Jf

\section{Introduction}

Over the past several years the physical properties of the members of sulphate series, $\mathrm{M}_{2} \mathrm{SO}_{4}$, and/or hydrogen sulphate family $\mathrm{MHSO}_{4}$ where $\mathrm{M}$ is a monovalent ion or group $\left(\mathrm{M}^{+}=\mathrm{Cs}^{+}, \mathrm{Rb}^{+}, \mathrm{K}^{+}, \mathrm{Na}^{+} \ldots\right.$ and/or $\left.\mathrm{NH}_{4}^{+}\right)$, have been receiving much attention of several investigators owing to their interesting properties. These compounds undergo several structural phase transitions at low and high temperatures [1-7]. Some members of these two series show ferroelectric phase transitions [8]. 
To our surprise much less attention has been devoted to the related two series of sulphate compounds $\mathrm{DSO}_{4} \cdot x \mathrm{H}_{2} \mathrm{O}$ and $\mathrm{T}_{2}\left(\mathrm{SO}_{4}\right)_{3} \cdot x \mathrm{H}_{2} \mathrm{O}$ where $\mathrm{D}$ is a divalent element $(\mathrm{D}=\mathrm{Hg}$ (II), $\mathrm{Pb}$ (II),$\ldots$ and $\mathrm{T}$ is a trivalent ion i.e. $\mathrm{Ce}(\mathrm{III})$ and $x$ is the number of water molecules $(x=0,1,2, \ldots)$.

The crystal structures of some members of the sulphate series were previously determined [9-12]. The most interesting group in the structures of these compounds is the sulphate group $\mathrm{SO}_{4}$ which is usually found to arrange in tetrahedral or polyhedral symmetries. The existence of water molecules in these compounds leads to the formation of the hydrogen bonding of the type $\mathrm{O}-\mathrm{H} . . . \mathrm{O}$.

In the previous work we investigated the phase transition in ammonium perulphate, $\left(\mathrm{NH}_{4}\right)_{2} \mathrm{~S}_{2} \mathrm{O}_{8}$ [13]. The persulphate group, $\mathrm{S}_{2} \mathrm{O}_{8}$, consists of two sulphate roups $\left(2 \mathrm{SO}_{4}\right)$. In this paper we report on the electrical conductivity $\sigma$, the thernal conductivity $\lambda$ and the DTA thermogram for two sulphate compounds, $\mathrm{HgSO}_{4}$ nd $\mathrm{Ce}_{2}\left(\mathrm{SO}_{4}\right)_{3} \cdot \mathrm{H}_{2} \mathrm{O}$, as a representation of the two mentioned series $\mathrm{DSO}_{4} \cdot x \mathrm{H}_{2} \mathrm{O}$ ind $\mathrm{T}_{2}\left(\mathrm{SO}_{4}\right)_{3} \cdot x \mathrm{H}_{2} \mathrm{O}$. To the best of our knowledge these properties have not et been investigated. By studying the thermal conductivity one can propose the nechanism of heat transfer, e.g. whether the thermal conduction is mainly due to lectronic or phonon processes.

\section{Experimental}

The materials used in the present work were manufactured by the British rug Houses Ltd. The purity of each salt is about $99 \%$, the product number of le $\mathrm{HgSO}_{4}$ salt is 29174 and that of the $\mathrm{Ce}_{2}\left(\mathrm{SO}_{4}\right)_{3} \cdot \mathrm{H}_{2} \mathrm{O}$ salt is 27662 .

For electrical measurements, the fine-grounded powder of each salt was comessed under a pressure of $\approx 5 \mathrm{t} / \mathrm{cm}^{2}$ to form discs (pellets) of diameter $\approx 1.5 \mathrm{~cm}$ $1 \mathrm{~d}$ of thickness $\approx 1.5 \mathrm{~mm}$. The density of the compressed sample of $\mathrm{HgSO}_{4}$ is $50 \mathrm{~g} / \mathrm{cm}^{3}$ while that of the $\mathrm{Ce}_{2}\left(\mathrm{SO}_{4}\right)_{3} \cdot \mathrm{H}_{2} \mathrm{O}$ is $3.20 \mathrm{~g} / \mathrm{cm}^{3}$ (the standard densities e $6.47 \mathrm{~g} / \mathrm{cm}^{3}$ and $3.17 \mathrm{~g} / \mathrm{cm}^{3}$ respectively [14]).

The electrical resistance was measured using Keithley type 617 programmable sctrometer. A sample holder with brass electrodes was specially designed to fit e present electrical measurements. Good contact was attained by painting both ses of the sample with air-drying conducting silver paste (type RC, made in the k). Measurements of the sample temperature were performed using a thermocou$z$ attached to the sample. The electrical conductivity $\sigma$ was calculated from the lue of resistance $(R)$ and the geometry of the sample. The DTA measurements re carried out on the powdered samples to check the transition temperature.

The apparatus used for thermal conductivity measurements is shown in 3. 1. The details of this method were given elsewhere [15-16]. The temperature idient across the sample was measured using $\mathrm{NiCr}-\mathrm{Ni}$ differential thermocou. The heat transferred through the sample from the lower surface to the upper face was controlled by the heating current of the furnace to maintain the deid temperature. The degree of vacuum inside the system is $10^{-3} \mathrm{~mm} \mathrm{Hg}$. The erimental error in the thermal conductivity measurement is about $3 \%$. 


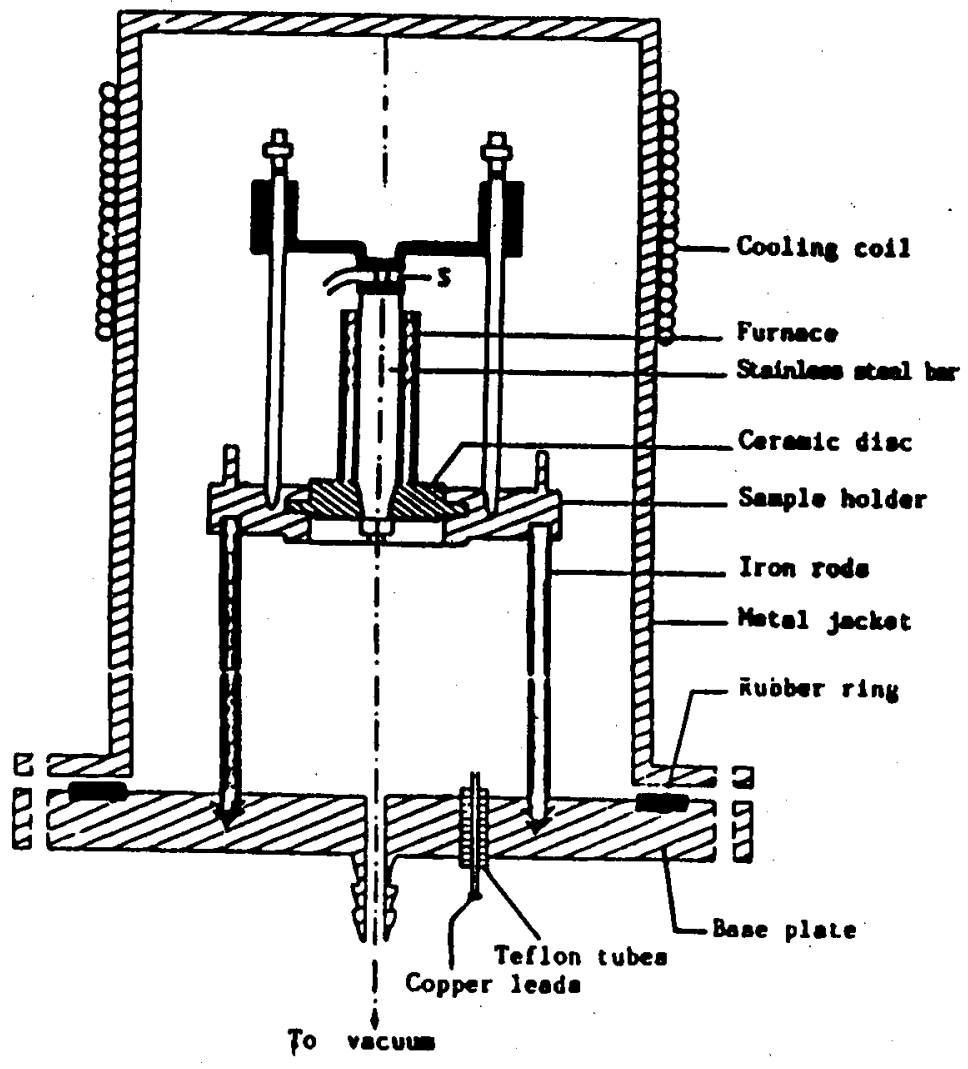

Fig. 1. The apparatus used for thermal conductivity measurements.

\section{Results}

Figure 2a shows the variation of the electrical conductivity $\sigma$ with temperature $40<T<120^{\circ} \mathrm{C}$ of $\mathrm{HgSO}_{4}$. As one can observe from Fig. 2a, the conductivity $\sigma$ decreases sharply with increasing temperature up to $\approx 75^{\circ} \mathrm{C}$. As the temperature exceeds this value, the rate of decrease in $\sigma$ with temperature becomes very slow resulting in the minimum value of $\sigma$ at temperature of about $90^{\circ} \mathrm{C}$ and then increases with temperature. The plot of $\sigma$ vs. $T$ suggests a structural phase transition at temperature of $\approx 90^{\circ} \mathrm{C}$.

Figure $2 \mathrm{~b}$ represents the same relation for the compound $\mathrm{Ce}_{2}\left(\mathrm{SO}_{4}\right)_{3} \cdot \mathrm{H}_{2} \mathrm{O}$. The plot is characterized by a gradual increase in the values of $\sigma$ as the temperature is increased up to $90^{\circ} \mathrm{C}$ where the electrical conductivity $\sigma$ reaches its maximum value. A sharp decrease in $\sigma$ values was observed as the temperature exceeds $100^{\circ} \mathrm{C}$. This behaviour suggests a structural phase transition at $\approx 90^{\circ} \mathrm{C}$.

Figures $3 \mathrm{a}$ and $3 \mathrm{~b}$ show the Arrhenius plots $\left(\ln \sigma\right.$ against $\left.10^{3} / T\right)$ for the $\mathrm{IIgSO}_{4}$ and $\mathrm{Ce}_{2}\left(\mathrm{SO}_{4}\right)_{3} \cdot \mathrm{H}_{2} \mathrm{O}$ respectively. Each plot is characterized by two straight lines of different slopes. From each plot we calculated the activation energy of 

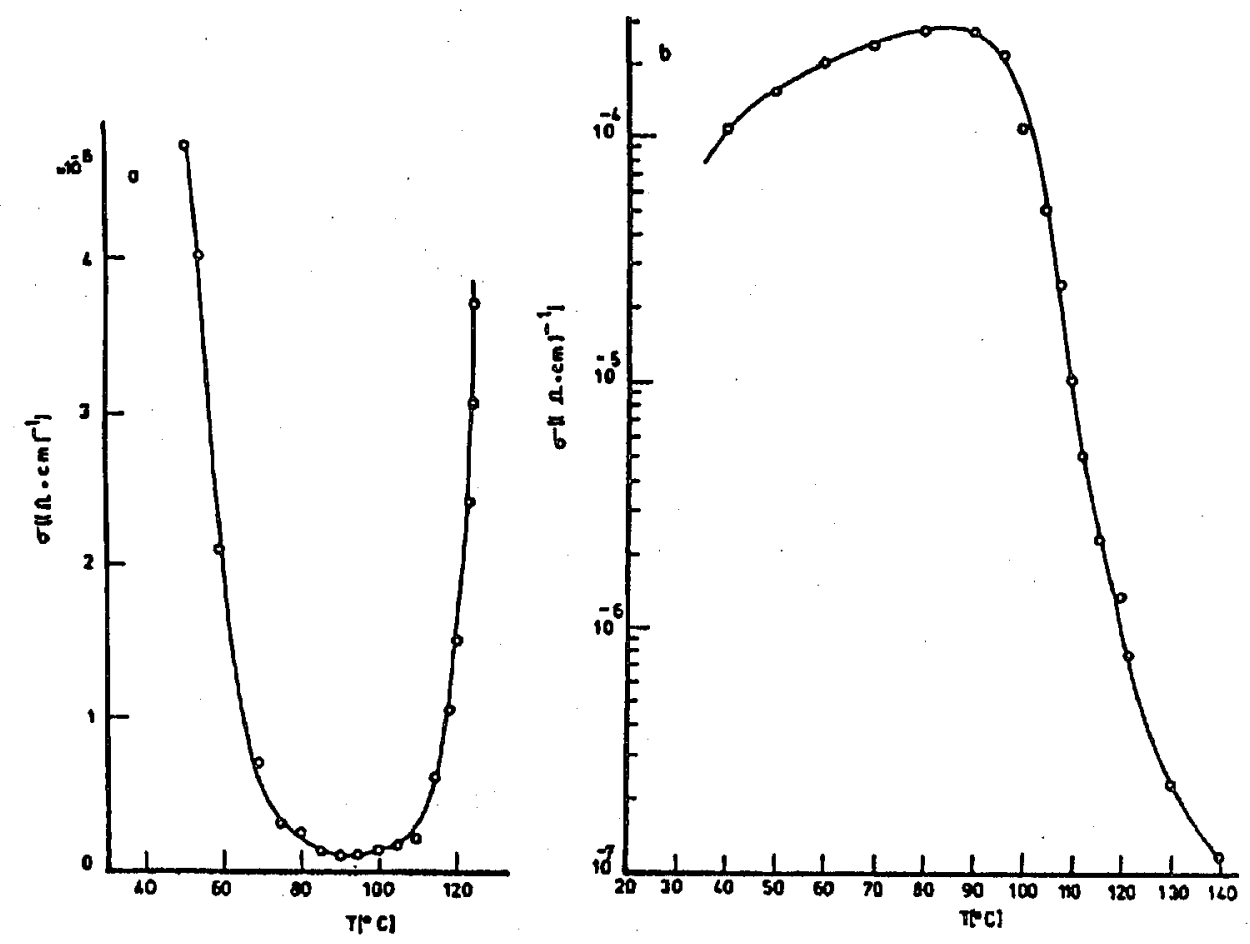

Fig. 2. Variation of the electrical conductivity $\sigma$ with temperature for (a) mercury(II) sulphate, $\mathrm{HgSO}_{4}$, (b) cerous(III) sulphate $\mathrm{Ce}_{2}\left(\mathrm{SO}_{4}\right)_{3} \cdot \mathrm{H}_{2} \mathrm{O}$.

each phase of the two salts. These calculations yield the values $E_{1}=-1.8 \mathrm{eV}$, $E_{2}=1.52 \mathrm{eV}$ for $\mathrm{HgSO}_{4}$, while for the $\mathrm{Ce}_{2}\left(\mathrm{SO}_{4}\right)_{3} \cdot \mathrm{H}_{2} \mathrm{O}$ the obtained values are $E_{1}=1.37 \mathrm{eV}$ and $E_{2}=-0.24 \mathrm{eV}$. These values agree quite well with that of other sulphate salts. For example, the values of the activation energies of $\mathrm{Na}_{2} \mathrm{SO}_{4}$ are $1.16 \mathrm{eV}$ and $0.56 \mathrm{eV}[17]$.

Among other things, the change of the values of $E_{1}$ and $E_{2}$ for each compound both in magnitude and sign is an indication for the occurrence of the structural phase transition. Furthermore, the negative sign of the activation energy means that the conductivity corresponding to this phase is not thermally activated. Another interesting fact is that the two lines of each plot intersect at $T \approx 90^{\circ} \mathrm{C}$ $\left(10^{3} / T \approx 2.75\right.$ or $T \approx 363.64 \mathrm{~K}$ or $\left.T \approx 90.47^{\circ} \mathrm{C}\right)$.

The variation of the thermal conductivity $\lambda$ as a function of temperature $40<T<140^{\circ} \mathrm{C}$ for the two compounds, $\mathrm{HgSO}_{4}$ and $\mathrm{Ce}_{2}\left(\mathrm{SO}_{4}\right)_{3} \cdot \mathrm{H}_{2} \mathrm{O}$, is shown in Figs. $4 \mathrm{a}$ and $4 \mathrm{~b}$ respectively. The two plots have nearly the same general trends. In other words, the general feature of each plot is that there is a gradual decrease in the values of $\lambda$ as the temperature increases up to a temperature of about $90^{\circ} \mathrm{C}$, where the value of $\lambda$ reaches its minimum value and then begins to increase once again. Among other things, the behaviour of the measured thermal conductivity $\lambda$ for each of the two investigated compounds confirms and supports the 

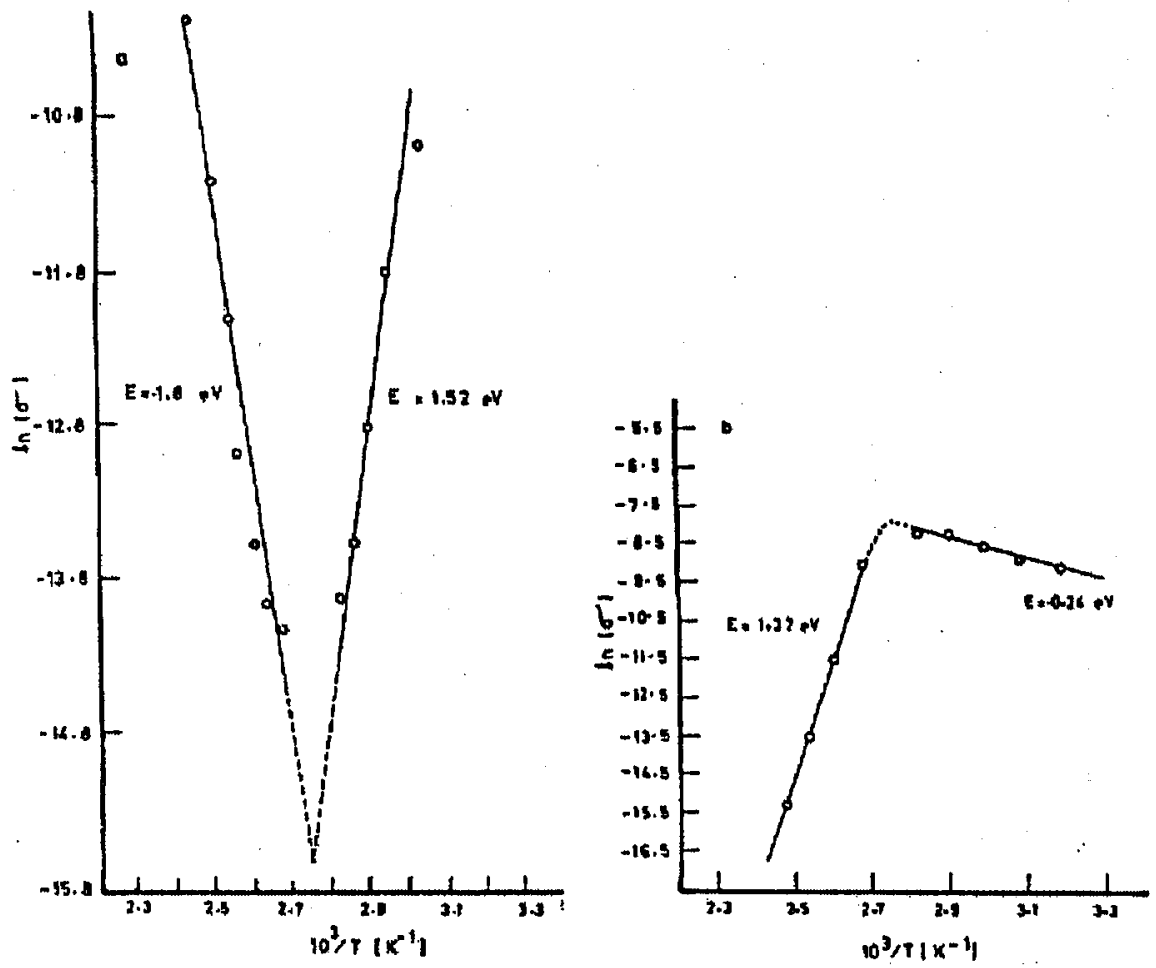

Fig. 3. Relationship between $\ln \sigma$ vs. $10^{3} / T$ for (a) mercury(II) sulphate, $\mathrm{HgSO}_{4}$, (b) cerous(III) sulphate $\mathrm{Ce}_{2}\left(\mathrm{SO}_{4}\right)_{3} \cdot \mathrm{H}_{2} \mathrm{O}$.
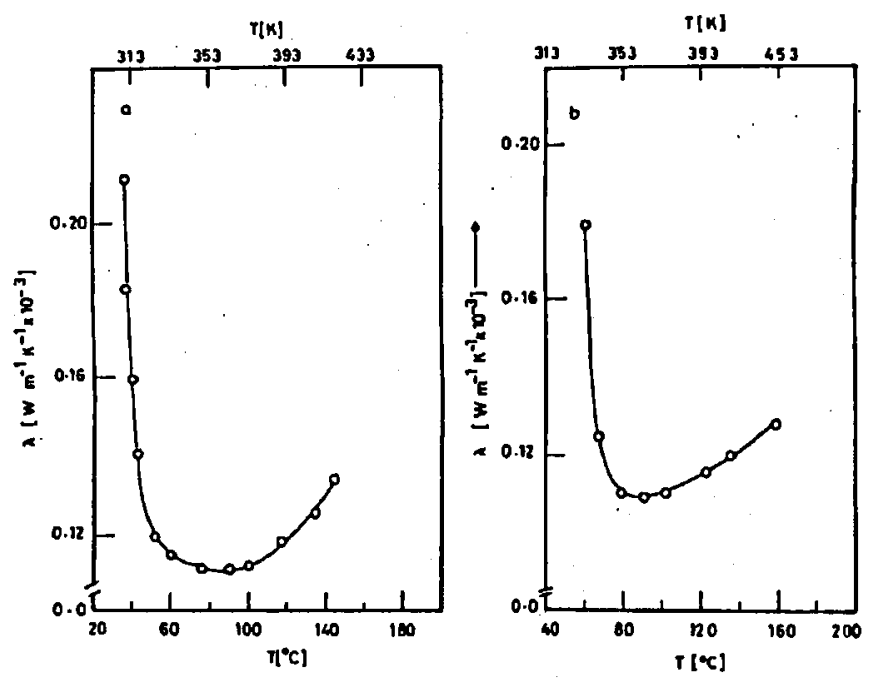

Fig. 4. Variation of the thermal conductivity $\lambda$ with temperature for (a) mercury(II) sulphate, $\mathrm{HgSO}_{4}$, (b) cerous(III) sulphate $\mathrm{Ce}_{2}\left(\mathrm{SO}_{4}\right)_{3} \cdot \mathrm{H}_{2} \mathrm{O}$. 
possibility of the occurrence of phase transition at $\approx 90^{\circ} \mathrm{C}$ which was observed from the measured electrical conductivity. Another interesting fact is that the order of magnitude of $\lambda$ suggests that the two investigated salts behave almost as poorly conducting materials.

The proposed phase transitions in the two salts are confirmed by performing the differential thermal analysis in the same temperature range. The DTA thermograms resulting from such analysis are shown in Figs. $5 \mathrm{a}$ and $5 \mathrm{~b}$. The heating rate
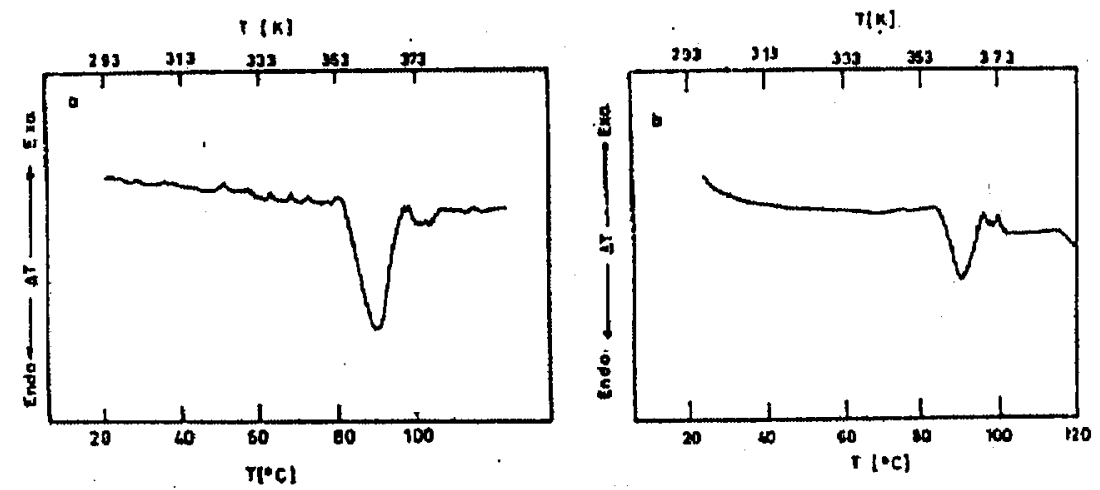

Fig. 5. The DTA thermograms for (a) mercury(II) sulphate, $\mathrm{HgSO}_{4}$, (b) cerous(III) sulphate $\mathrm{Ce}_{2}\left(\mathrm{SO}_{4}\right)_{3} \cdot \mathrm{H}_{2} \mathrm{O}$.

is $10^{\circ} \mathrm{C} \cdot \mathrm{min}^{-1}$ and the sensitivity $\Delta T$ is $10 \mathrm{mV} \cdot \mathrm{cm}^{-1}$. As one can observe, each thermogram is characterized by an endothermic peak centred at a temperature of $\approx 90^{\circ} \mathrm{C}$. This can be considered as a good evidence and a final confirmation for the proposed phase transition.

\section{Discussion}

Based on the measured electrical and thermal parameters presented in this work, combined with the DTA thermograms, one can clearly suggest that each of the two salts undergoes structural phase transition at about $90^{\circ} \mathrm{C}$.

For the anhydrous mercury(II) sulphate, $\mathrm{HgSO}_{4}$, the chemical formula does not contain any water molecules and the sample is not hygroscopic, in other words, the observed phase transition is not due to the loss of water (dehydration). For the cerous(III) sulphate no loss of weight was observed upon heating the samples from room temperature up to $70,75, \ldots$ and $90^{\circ} \mathrm{C}$. This means no loss of water (dehydration) at the above mentioned temperatures. Thus the observed phase transition in each of the two salts is of structural origin.

As mentioned before, the crystal structure of the $\mathrm{HgSO}_{4}$ was determined [9]. The crystals are orthorhombic with $a=4.785, b=4.821, c=6.581 \AA$ and space group $P n 2_{1} m$. The bivalent $(\mathrm{Hg})$ ion is surrounded by four oxygen atoms in the form of a very distorted tetrahedron [9]. To the best of our knowledge, the crystal structure of the $\mathrm{Ce}_{2}\left(\mathrm{SO}_{4}\right)_{3} \cdot \mathrm{H}_{2} \mathrm{O}$ has not yet been determined. However, the most interesting group in this salt is the $\mathrm{SO}_{4}$ group in addition to water molecule. The 
latter will result in the formation of hydrogen bond of the type O-H...O. The change in hydrogen bonding scheme is the primary cause of the phase transition in some sulphate and/or persulphate compounds $[18,13]$.

For the two compounds the common group is the $\mathrm{SO}_{4}$ group. $\mathrm{It}$ is well known that this group is characterized by reorientational motion. Thus, as the temperature is increased from room temperature and is approaching $90^{\circ} \mathrm{C}$, the thermal energy absorbed by the salt is high enough to activate the reorientational motion of the $\mathrm{SO}_{4}$ group to another equivalent position. This reorientational motion will affect the arrangement of the molecule as a whole resulting in the observed phase transition. Another interesting problem is the mechanism of heat transfer.

In general, the thermal conductivity $\lambda$ of such poorly conducting materials can be expressed by phononic and electronic modes of heat conduction. In other words

$$
\lambda=\lambda_{\mathrm{ph}}+\lambda_{\mathrm{e}}
$$

where $\lambda_{\mathrm{ph}}$ is the contribution of the lattice vibrations (phonons) to the thermal conductivity and $\lambda_{e}$ is the electronic part of the thermal conductivity. The latter depends on the electrical conductivity of the material.

Although the order of magnitude of $\lambda$ may suggest that the two investigated salts behave almost as poorly conducting materials, yet the basic criterion for evaluation of electron contribution in heat transport is a comparison of the Lorenz number with the theoretical value $L_{0}=2.45 \times 10^{-8} \mathrm{~W} \cdot \Omega / \mathrm{K}^{2}$. For further clarification we shall suggest first the validity of Weidmann-Franz law for these salts. According to this law, the electronic part $\lambda_{e}$ is related to the electrical conductivity $\sigma$ by the equation

$$
\lambda_{\mathrm{e}}=L_{0} \sigma T,
$$

where $T$ is the absolute temperature. Using the measured $\sigma$ values at different temperatures one can calculate the values of $\lambda_{e}$ at the same temperatures. For the compound $\mathrm{HgSO}_{4}$ the $\sigma$ values at temperatures $333 \mathrm{~K}, 363 \mathrm{~K}$ and $393 \mathrm{~K}$ are $\approx 2 \times 10^{-8}(\Omega \cdot \mathrm{m})^{-1}, 0.15 \times 10^{-8}(\Omega \cdot \mathrm{m})^{-1}$ and $1.5 \times 10^{-8}(\Omega \cdot \mathrm{m})^{-1}$, respectively. Thus the corresponding $\lambda_{\mathrm{e}}$ values are

$$
\begin{aligned}
& \lambda_{\mathrm{e}}(333 \mathrm{~K})=0.8 \times 10^{-12} \mathrm{~W} \cdot \mathrm{m}^{-1} \cdot \mathrm{K}^{-1} \\
& \lambda_{\mathrm{e}}(363 \mathrm{~K})=0.013 \times 10^{-12} \mathrm{~W} \cdot \mathrm{m}^{-1} \cdot \mathrm{K}^{-1}
\end{aligned}
$$

and

$$
\lambda_{\mathrm{e}}(393 \mathrm{~K})=0.1 \times 10^{-12} \mathrm{~W} \cdot \mathrm{m}^{-1} \cdot \mathrm{K}^{-1} .
$$

Similarly for the compound $\mathrm{Ce}_{2}\left(\mathrm{SO}_{4}\right)_{3} \cdot \mathrm{H}_{2} \mathrm{O}$

$$
\begin{aligned}
& \lambda_{\mathrm{e}}(333 \mathrm{~K})=0.8 \times 10^{-12} \mathrm{~W} \cdot \mathrm{m}^{-1} \cdot \mathrm{K}^{-1} \\
& \lambda_{\mathrm{e}}(363 \mathrm{~K})=13.3 \times 10^{-12} \mathrm{~W} \cdot \mathrm{m}^{-1} \cdot \mathrm{K}^{-1}
\end{aligned}
$$

and

$$
\lambda_{\mathrm{e}}(393 \mathrm{~K})=0.90 \times 10^{-12} \mathrm{~W} \cdot \mathrm{m}^{-1} \cdot \mathrm{K}^{-1} .
$$


From these calculations it is clear that the values of $\lambda_{e}$ for any of the two salts are very small compared with the values of $\lambda$ (see Figs. 4a, 4b) and/or the Lorénz number $\left(L_{0}\right)$.

The conclusion we could arrive at is that the two salts behave almost as poorly conducting materials and therefore the mechanism of the heat transport is due to phonons and thus

$$
\lambda \sim \lambda_{\mathrm{ph}} \text {. }
$$

Finally, X-ray structural analysis of the $\mathrm{Ce}_{2}\left(\mathrm{SO}_{4}\right)_{3} \cdot \mathrm{H}_{2} \mathrm{O}$ and the study of other properties of these two sulphate salts such as optical spectroscopy and light scattering experiments are needed in order to give a clear view of the reorientional motion of the $\mathrm{SO}_{4}$ group.

\section{References}

[1] B.K. Choi, D.J. Lockwood, Solid State Commun. 72, 133 (1989) and references therein.

[2] B.K. Choi, D.J. Lockwood, Phys. Rev. B 40, 4683 (1989) and references therein.

[3] Y.A. Badr, S. Awad, J. Phys. Chem. Solids 45, 350 (1984).

[4] A. Sawada, S. Ohya, Y. Ishubashi, Y.J. Takagi, J. Phys. Soc. Jpn. 38, 1408 (1975).

[5] Y.S. Jain, H.-D. Bist, G.C. Upreti, Chem. Phys. Lett. 22, 572 (1973).

[6] K.J. Rao, C.N.R. Rao, J. Mater. Sci. 1, 238 (1966).

[7] C.J.H. Schutte, A. Heyns, J. Chem. Phys. 52, 864 (1970).

[8] R. Repinsky, K. Vedam, Phys. Rev. 117, 1502 (1960).

[9] P.A. Kokkoros, P.J. Rentzeperies, Z. Kristallogr. 119, 509 (1963).

[10] J.M. Bregeault, P. Herpin, Bull. Soc. Fr., Mineral Cristallogr. 93, 37 (1970).

[11] H. Naruse, K. Tanaka, H. Morikawa, F. Marumo, B.N. Behrotra, Acta Crystallogr. B 43, 143 (1987).

[12] C. Stalhandske, Acta Crystallogr. B 36, 23 (1980).

[13] M.M. Abdel-Kader, M.M. Mosaad, F. El-Kabbany, Phys. Status Solidi A 130, 351 (1992).

[14] R.C. Weast, M.J. Astle, Handbook of Chemistry and Physics, 62nd ed., CRC Press, Boca Raton 1981/1982, pp. B-120 and B-91.

[15] T.O. Moson, H.K. Bowen, J. Am. Ceram. Soc. 64, 237 (1981).

[16] H.L. Tuller, A.S. Nowick, J. Phys. Chem. Solids 38, 859 (1977).

[17] F. El-Kabbany, Y. Badr, M. Tosson, Phys. Status Solidi A 63, 699 (1981).

[18] E.O. Schemper, W.C. Hamilton, J. Chem. Phys. 44, 448 (1966). 